\title{
Pengaruh Fraksi Berat Serbuk Alumina Terhadap Porositas Busa Aluminium Hasil Injeksi Gas
}

\author{
Edy Yulianto \\ Balai Teknologi Mesin Perkakas Produksi dan Otomasi (BTMEPPO) - Badan Pengkajian dan \\ Penerapan Teknologi (BPPT), Indonesia, 15314 \\ edy.yulianto@bppt.go.id
}

\begin{abstract}
Aluminum foam is a very interesting material to develop. This material is a material that has a combination of characteristics between physical and mechanical properties such as high stiffness and low density. There are several processes for making aluminum foam that have been developed, either through the liquid, solid, or gas phases. And of these various processes, the process of making aluminum foam through the liquid phase by using the gas injection method is the simplest and cheapest process. The principle of the process of making aluminum foam with this method is that bubbles are produced from the process of blowing the gas into the aluminum liquid in which there are additive particles that function as a bubble stabilizer. These stable bubbles will become pores after the aluminum liquid solidifies. This research will discuss the effect of the weight fraction of alumina powder with an average size of $5.77 \mu \mathrm{m}$ added to liquid aluminum on the macro-pore structure in the form of shape and size as well as the spread of the resulting pores. And the result is that the optimal weight fraction of adding alumina powder is $15 \%$, where the resulting pores have a more homogeneous and evenly shaped and sized.
\end{abstract}

Keyword: alumina, aluminum foam, injection

\section{PENDAHULUAN}

Busa alumunium mulai diproduksi pada tahun 1950, dan pada tahun 1980 mulai dikembangkan beberapa metode pembuatan busa aluminium baik lewat fasa cair maupun padat untuk memenuhi keperluan industri sebagai material struktur ringan, peredam suara, dan penyerap energi, baik di bidang konstruksi maupun industri transportasi [1, 2-5], dan juga material penghalang panas (thermal insulation) yang baik[6].

Pembuatan busa aluminium melalui fasa cair dengan injeksi gas merupakan salah satu metoda yang sudah digunakan untuk kepentingan komersial. Metoda ini dikembangkan oleh Hydro Aluminium (Norwegia) dan Cymat Aluminium (Kanada). Pada metoda ini, seperti pada Gambar 2.3., digunakan serbuk silikon karbida (SiC), alumina $\left(\mathrm{Al}_{2} \mathrm{O}_{3}\right)$, atau magnesium oksida $\left(\mathrm{Mg}_{2} \mathrm{O}_{3}\right)$ sebagai partikel tambahan. Metoda ini dimulai dengan peleburan aluminium/ paduannya, setelah melebur sempurna, partikel tambahan dimasukkan ke dalam cairan aluminium, dan diaduk sehingga serbuk tersebut marata di seluruh cairan aluminium $[7,8]$. 


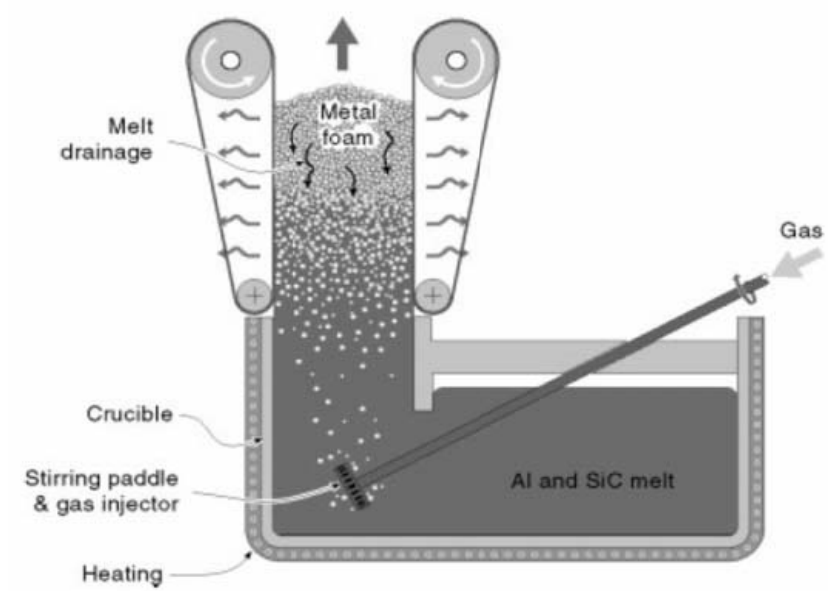

Gambar 1. Mekanisme pembuatan busa alumnium dengan metoda injeksi gas [9]

Serbuk oksida digunakan untuk menstabilkan gelembung di dalam cairan aluminium, dengan fraksi berat $5-15 \%$, dan ukuran serbuk $0,5-25$ mikron [10]. Dari penelitian lainnya disebutkan fraksi berat dan ukuran serbuk alumina yang digunakan adalah 10-20\% dengan ukuran 5-20 mikron[11].

Proses fabrikasi dilakukan dengan memasukkan serbuk oksida ke dalam cairan aluminium, dan dilakukan pengadukan untuk mencampurkan atau menyebarkan serbuk oksida di dalam cairan aluminium. Selanjutnya dilakukan proses peniupan gas (udara, nitrogen, atau argon) ke dalam cairan, sehingga menghasilkan gelembung gas yang tersebar dengan bagus. Gelembung yang terjadi akan mengapung di atas cairan aluminium, dan dikeluarkan dari untuk dilakukan proses pembekuan [7, 8].

Gas inert digunakan untuk menjaga agar busa aluminium yang dihasilkan tidak getas karena adanya oksida. Proses pembuatan dilakukan dekat dengan titik lebur aluminium yang digunakan untuk menjaga kekentalan cairan aluminium pada tingkat tertentu. Dari beberapa penelitian yang dilakukan, busa aluminium yang dihasilkan dari proses injeksi gas mempunyai pori-pori dari 3-25 mm, dan kerapatan 0,069 - 0.54 $\mathrm{g} / \mathrm{cm}^{3}[8]$.

Beberapa kelebihan metoda peniupan gas adalah sebagai berikut [12]:

- Murah dan proses produksinya paling sederhana

- Material dasar murah, dapat memakai sekrap MMC

- Ukuran dan kapasitas produksi besar

- Kerapatan dapat dikontrol dengan baik

- Pori yang terbentuk jenis pori tertutup

Sedangkan kelemahan dari metoda ini adalah sebagai berikut [12] :

- Kurang bagus untuk bentuk komponen yang agak kompleks

- Adanya partikel oksida ( $\mathrm{SiC}, \mathrm{Al}_{2} \mathrm{O}_{3}$, atau $\mathrm{Mg}_{2} \mathrm{O}_{3}$ ) menyebabkan proses pemotongan dan permesinan agak sulit.

Penelitian ini dilakukan untuk menghasilkan parameter optimal fraksi serbuk alumina sebagai material penstabil gelembung gas dalam cairan aluminium, sehingga dihasilkan busa aluminium dengan bentuk dan ukuran pori yang seragam.

\section{METODE PENELITIAN}

Penelitian ini dilakukan dengan menggunakan skema eksperimen seperti pada Gambar 2. Material dasar yang digunakan pada penelitian ini adalah Al-12Mg dan 
partikel penstabil gelembung serbuk alumina dengan ukuran rata-rata 5,77 $\mu \mathrm{m}$ dengan fraksi berat $0-20 \%$.

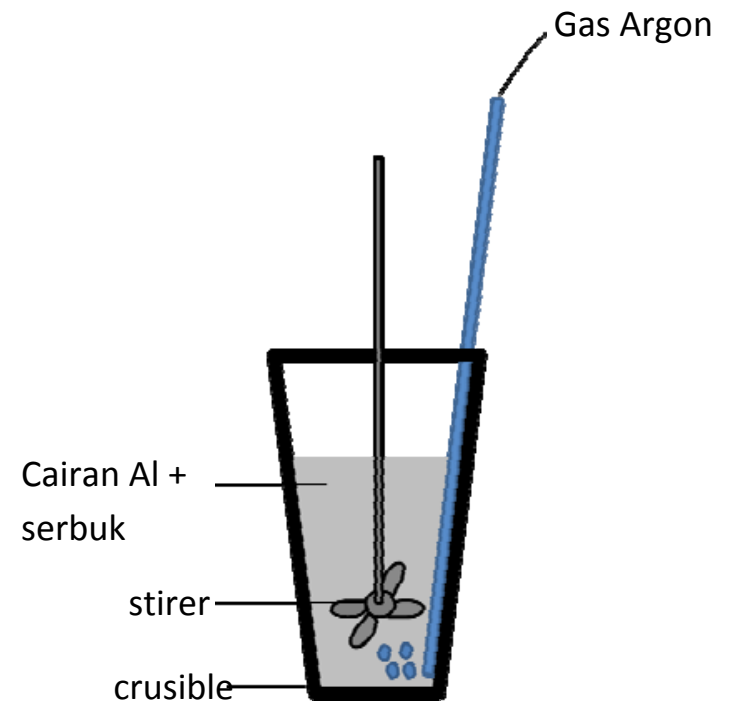

Gambar 2. Setup peralatan untuk eksperimen

Material dasar Al-12Mg dan serbuk alumina dipanaskan dengan suhu $680^{\circ} \mathrm{C}$ dalam krusibel berukuran sekitar $500 \mathrm{cc}$. Kemudian dilanjutkan proses pengadukan dengan stirrer yang terbuat dari stainless steel selama 10 menit. Selanjutnya dilakukan proses injeksi gas argon melalui pipa stainless steel berdiameter $1 \mathrm{~mm}$ pada saat cairan aluminium bersuhu $631^{\circ} \mathrm{C}$ selama kurang lebih 3 menit dengan aliran gas $0,5 \mathrm{l} / \mathrm{menit}$. Setelah proses injeksi gas, proses selanjutnya adalah proses pembekuan dari cairan aluminium, dan diharapkan diperoleh busa aluminium dari proses ini.

Untuk mengetahui busa aluminium dari eksperimen ini dilakukan observasi untuk mengetahui karakteristik pori dalam busa aluminium, yang berupa ukuran dan bentuk pori serta penyebarannya.

\section{HASIL PENELITIAN DAN PEMBAHASAN}

Hasil dari percobaan fabrikasi busa aluminium dengan metoda injeksi gas pada penelitian ini dapat dilihat pada Gambar 3, dan dijelaskan lebih detil pada Tabel 1. Percobaan ini dilakukan dengan mencairkan Al-12Mg pada suhu $680^{\circ} \mathrm{C}$, dan dilakukan penambahan serbuk alumina dengan ukuran rata-rata 5,77 $\mu \mathrm{m}$ dan fraksi berat $0,5,10$, 15 , dan $20 \%$.

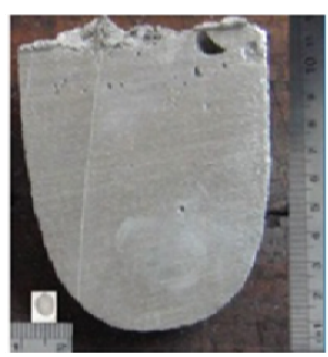

(a)

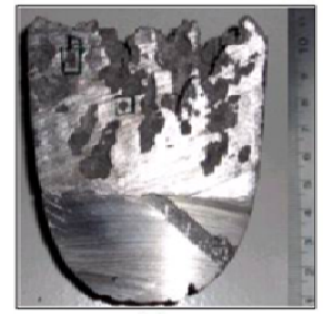

(b)

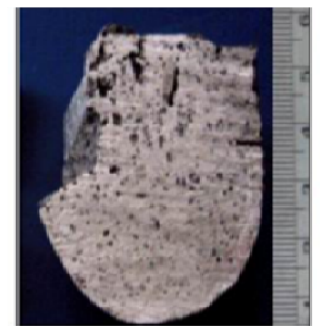

(d)

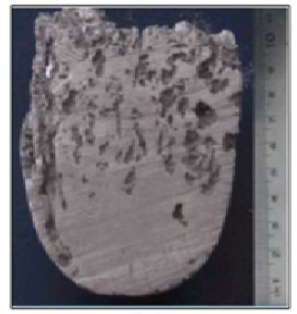

(c)

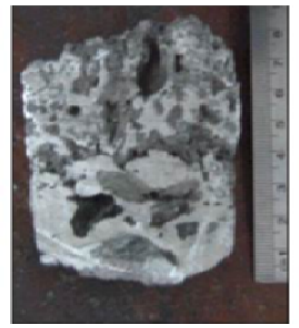

(e)

Gambar 3. Hasil Pembuatan Busa Aluminium dengan penambahan Serbuk Alumina 5,77 $\mu \mathrm{m}$, Fraksi Berat serbuk alumina (a) $0 \%$, (b) $5 \%$, (c) $10 \%$, (d) $15 \%$, dan (e) $20 \%$ 
Tabel 1. Struktur makro pori busa aluminium hasil pengujian

\begin{tabular}{|c|c|c|}
\hline $\begin{array}{c}\text { Fraksi Berat } \\
\text { Serbuk } \\
\text { Alumina (\%) }\end{array}$ & $\begin{array}{c}\text { Ukuran Pori } \\
\mathbf{( m m )}\end{array}$ & Penyebaran Pori \\
\hline 0 & 1,85 & Tidak Merata \\
\hline 5 & 3,80 & Merata \\
\hline 10 & 2,50 & Merata \\
\hline 15 & 1,28 & Merata \\
\hline 20 & 2,10 & Merata \\
\hline
\end{tabular}

Pada hasil eksperimen fabrikasi busa aluminium dengan injeksi gas tanpa penambahan serbuk alumina (fraksi berat $0 \%$ ), pori yang terbentuk bukan merupakan pengaruh adanya penambahan serbuk alumina sebagai partikel penstabil gelembung, tetapi terjadi karena proses pendinginan cairan paduan aluminium, dimana cairan paduan Al-12Mg membeku pada saat gelembung hasil peniupan gas masih berada di dalamnya, sehingga terbentuklah pori. Dengan lubang pipa peniup berdiameter $1 \mathrm{~mm}$, dihasilkan rata-rata ukuran pori yang kecil, yaitu $1,85 \mathrm{~mm}$.

Ukuran pori yang kecil ini disebabkan cairan paduan aluminium mempunyai kekentalan yang rendah, dimana kekentalan cairan sangat mempengaruhi ukuran gelembung gas dalam cairan, pada cairan dengan kekentalan rendah akan lebih mudah menghasilkan gelembung dengan ukuran kecil disbanding cairan kekentalan tinggi. Karena tidak adanya serbuk alumina dalam cairan, maka cairan mempunyai kekentalan rendah, dan lebih mudah menghasilkan pori dengan ukuran yang kecil.

Eksperimen fabrikasi busa aluminium dengan injeksi gas dengan penambahan fraksi berat 5\% serbuk alumina fraksi, dihasilkan pori memanjang dengan diameter rata-rata sebesar 3,8 mm. Ukuran pori ini terbentuk karena proses peniupan gas argon menghasilkan gelembung yang kurang stabil, sehingga gelembung akan mudah pecah. Apabila gelembung masih di dalam cairan aluminium, maka gelembung yang kurang stabil ini akan bergabung dengan gelembung lain menjadi gelembung dengan ukuran yang lebih besar. Dan bentuk pori yang memanjang dikarenakan sebelum gelembung yang saling bergabung membentuk gelembung yang berbentuk bulat, cairan sudah mengalami pembekuan. Sehingga pori yang dihasilkan berbentuk bulat memanjang.

Untuk eksperimen fabrikasi busa aluminium dengan injeksi gas dengan fraksi berat serbuk alumina $10 \%$, pori yang terbentuk pori memanjang dengan diameter rata-rata 2,5 $\mathrm{mm}$. Bentuk pori yang demikian terjadi karena adanya gelembung yang stabil dan gelembung yang kurang stabil. Dimana gelembung stabil akan menghasilkan pori yang kecil dan berbentuk bulat, dan gelembung yang kurang stabil akan menghasilkan pori yang berukuran lebih besar atau memanjang karena pori ini merupakan gabungan dari beberapa gelembung yang kurang stabil.

Pada eksperimen fabrikasi busa aluminium dengan injeksi gas penambahan serbuk alumina dengan fraksi berat $15 \%$ menghasilkan pori yang hampir semuanya berbentuk bulat dan kecil., dengan ukuran pori rata-rata sebesar 1,28 mm. Hal ini menunjukkan bahwa dengan penambahan serbuk alumina pada paduan Al-12Mg sebesar $15 \%$ menghasilkan gelembung yang hampir semuanya stabil, dan hanya sebagian kecil saja yang kurang stabil. 




Gambar 4. Grafik Pengaruh Fraksi Berat Serbuk Alumina terhadap Jarak Daerah Penyebaran Pori dari Dasar Hasil Coran

Pada eksperimen fabrikasi busa aluminium dengan injeksi gas penambahan fraksi berat serbuk alumina $20 \%$ menghasilkan pori berbentuk bulat dengan diameter rata-rata 2,1 . Ukuran pori rata-rata sampel ini lebih besar daripada dengan penambahan fraksi berat $15 \%$, karena pada sampel ini penambahan serbuk alumina sebesar $20 \%$ menyebabkan kekentalan cairan paduan $\mathrm{Al}-12 \mathrm{Mg}$ menjadi terlalu besar, sehingga walaupun gelembung dalam cairan paduan Al-12Mg stabil, tetapi karena kekentalan terlalu tinggi, dan tekanan peniupan gas kecil (dibuat konstan), maka gelembung yang keluar dari pipa mempunyai ukuran yang besar karena merupakan akumulasi dari aliran gas yang tertahan oleh cairan.

Penyebaran pori yang terjadi dalam busa aluminium yang dihasilkan dapat dilihat pada grafik di Gambar 4. Hasil eksperimen fabrikasi busa aluminium dengan injeksi gas tanpa penambahan serbuk alumina (fraksi berat $0 \%$ ), jarak pori terbawah pada daerah penyebaran pori adalah pada jarak $80 \mathrm{~mm}$ dari dasar. Jarak daerah penyebaran pori ini disebabkan oleh kekentalan cairan paduan aluminium yang rendah karena tidak adanya serbuk alumina di dalamnya, sehingga gelembung yang terbentuk akan lebih cepat bergerak menuju permukaan. Apabila kecepatan pembekuan tidak sebanding dengan kecepatan gelembung maka pori tidak akan terbentuk. Oleh sebab itu semakin tinggi cairan aluminium akan semakin memungkinkan terbentuknya pori.

Eksperimen fabrikasi busa aluminium dengan injeksi gas penambahan serbuk alumina akan menyebabkan kekentalan cairan paduan aluminium meningkat, sehingga kecepatan gelembung yang bergerak ke atas menjadi lebih pelan. Cairan paduan aluminium dengan fraksi berat serbuk alumina terbesar akan mempunyai jarak daerah penyebaran pori paling rendah, seperti terjadi pada sampel dengan fraksi berat serbuk alumina $15 \%$ dan $20 \%$.

Selain itu, semakin besar fraksi berat serbuk alumina, maka stabilitas gelembung akan lebih cepat terbentuk. Untuk menghasilkan gelembung stabil yang akhirnya menjadi pori, gelembung harus menempuh jarak tertentu untuk mengikat serbuk alumina dengan jumlah tertentu sehingga gelembung stabil, semakin banyak ukuran serbuk optimal yang terkandung dalam cairan paduan aluminium, maka jarak tempuh yang dibutuhkan untuk mencapai jumlah minimal agar gelembung stabil semakin pendek (rendah), sehingga penyebaran pori merata sampai bagian dasar sampel 


\section{KESIMPULAN}

Dari eksperimen yang sudah dilakukan, fabrikasi busa aluminium dengan metoda injeksi gas dengan penambahan serbuk alumina sebagai penstabil gelembung gas dalam cairan aluminium, diperoleh parameter fraksi berat serbuk alumina yang paling optimal yaitu sebesar $15 \%$. Dan dari fabrikasi dengan parameter ini dihasilkan ukuran pori yang homogeny dan merata dibandingkan dengan penambahan serbuk alumina dengan fraksi berat $0,5 \%, 10 \%$, dan $20 \%$.

Untuk menghasilkan busa aluminium dengan spesifikasi tertentu, sangat penting untuk melakukan kajian dan penelitian lebih lanjut, sehingga diketahui parameterparameter proses fabrikasi busa aluminium dengan metoda injeksi gas secara menyeluruh. Dimana selain parameter fraksi penambahan serbuk alumina sebagai penstabil gelembung dalam cairan aluminium, parameter suhu proses, kekentalan cairan aluminium, ukuran gelembung gas injeksi, dan parameter-parameter proses fabrikasi lainnya.

\section{REFERENSI}

[1] P. Schaeffler, et al., "Production, Properties, and Applications of Alulight ClosedCell Aluminum Foams", The Fifth International Workshop on Advanced Manufacturing Technologies, 2002, hal.1-8

[2] D.X.Sun, Y.Y.Zhao, "Phase Changes in Sintering of $\mathrm{Al} / \mathrm{Mg} / \mathrm{NaCl}$ Compacts for Manufacturing Al Foams by Sintering and Dissolution Process", Journal Materials Letters, 59, 2005, hal. 6-10

[3] Y.Y.Zhao, D.X.Sun, “A Novel Sintering-Dissolution Process for Manufacturing Al Foams", Journal Scripta Mater, 44, 2001, hal. 105-110

[4] Takashi Nakamura, et al., "Development of New Foaming Agent for Metal Foam", Materials Transactions, Vol. 43, No. 5, 2002, hal.1191-1196

[5] I. Budic, G. Solenicki, "Influencing Parameters on Homogenity of Aluminium Metal Foam AlSi12", Journal Metabk, 43(4), 2004, hal. 311-314

[6] John Banhart, "Metal Foams-from Fundamental Research to Applications", Frontiers in design of Materials, 2007, hal. 279-289

[7] John Banhart, "Manufacture, Characterization, and Application of Cellular Metals and Metal Foams", Progress in Materials Science, 46 (2001), hal. 559-632

[8] J. Banhart, “ Metallic Foams : Challenges and Opportunities”, Eurofoam, 2000, hal. $13-20$

[9] Haydn N.G.Wadley, “Cellular Metals Manufacturing”, Advanced Engineering Materials, 4(10), 2002, hal.726-733

[10] M. Ashby, et.al.' "Metal Foams : A Design Guide", Butterworth-Heinemann 2000, hal. 8

[11] John Banhart, "Metal Foams : The Mystery of Stabilisation", Hahn-Meitner Institute-Berlin, 2003.

[12] M. Ashby, et al., "Presentation Workshop on Metal Foams", NPL Cambidge University, 2000, hal. 9-26 